\title{
Assessment of knowledge and practice of menstrual hygiene among high school girls in Western Ethiopia
}

\author{
Shivaleela P. Upashe*, Tesfalidet Tekelab and Jalane Mekonnen
}

\begin{abstract}
Background: The issue of menstrual hygiene is inadequately acknowledged and has not received proper attention. Use of sanitary pads and washing the genital area are essential practices to keep the menstrual hygiene. Unhygienic menstrual practices can affect the health of the girls and there is an increased vulnerability to reproductive tract infections and pelvic inflammatory diseases and other complications. Therefore, the objective of this study was to assess the knowledge and practice of menstrual hygiene among high school girls at Nekemte town, Oromia region, Western Ethiopia.

Method: A school based cross-sectional study design was employed in Nekemte Town, Western Ethiopia. A multi stage sampling technique was used to select 828 female high school students. Data collection was carried out from May 04 to May 30, 2014 using a pre- tested structured questionnaire. The data were entered into a computer using Epi-info version 3.5.1 and then exported to SPSS for Windows version 20.0 for analysis. Bivariate and multivariate logistic regression analysis was done at $95 \%$ confidence interval.
\end{abstract}

Results: In this study, 504 (60.9\%) and 330 (39.9\%) respondents had good knowledge and practice of menstrual hygiene respectively. The findings of the study showed a significant positive association between good knowledge of menstruation and educational status of mothers ( $A O R=1.51,95 \% \mathrm{Cl}=1.02-2.22$ ), having radio/TV ( $A O R=2.42$, $95 \% \mathrm{Cl}: 1.64$ - 3.56). Educational status of the mother ( $A O R=2.03,95 \% \mathrm{Cl}=1.38-2.97$ ) and earning permanent pocket money from parents ( $A O R=2.73,95 \% \mathrm{Cl}=1.76-4.26$ ) revealed significant positive association with good practice of menstrual hygiene.

Conclusions: The findings showed that the knowledge and practice of menstrual hygiene is low. Awareness regarding the need for information about good menstrual practices is very important. So, health education program should be setup to create awareness and practice of good menstrual hygiene.

Keywords: Knowledge, Menstruation, Practice, Sanitary pads, Hygiene

\section{Background}

Adolescent girls constitute a vulnerable group not only with respect to their social status but also in relation to their health. In this regard, menstruation is regarded unclean or dirty in society [1]. The issue of menstrual hygiene is inadequately acknowledged and has not received proper attention [2]. Good hygienic practices, such as use of sanitary pads and adequate washing of the genital areas, are essential during menstruation

\footnotetext{
* Correspondence: spupashe@gmail.com

College of Medical and Health sciences, Wollega University, P.O. Box: 395, Nekemte, Oromia, Ethiopia
}

period. Women and girls of reproductive age need access to clean and soft absorbent sanitary products which in the long run protect their health from various infections [3]. To this effect, the practice of good menstrual hygiene reduces the incidence of reproductive tract infection (RTI). Thus, the consequences of RTIs are severe and may result in significant negative impact to a woman's health including chronic pelvic pain, dysmenorrhea (painful periods) and in severe cases infertility. Reproductive tract infections, which have become a silent epidemic that devastates women's lives is closely related to poor menstrual hygiene $[1,4]$. 
Every year approximately $10 \%$ of women worldwide are exposed to genital infections including urinary tract infections and bacterial vaginosis, and $75 \%$ of women have a history of a genital infection. Specifically, the common risk factors for vaginal infections include pregnancy and poor hygiene (both perineal and menstrual hygiene) [5].

Studies in Africa have found out the use of sanitary pads as low as $18 \%$ amongst Tanzanian women with the remainder using cloth or toilet paper [6]. Studies of Nigerian schoolgirls have found between 31 and $56 \%$ using toilet tissue or cloth to absorb their menstrual blood as opposed to menstrual pads [7, 8].

A study conducted in Ethiopia showed that, though, most (92\%) students were aware of menstruation before menarche, their utilization of sanitary napkins was low at $37.6 \%$ and a significant proportion, $62.4 \%$ were using rags and pieces of cloth [9]. Eleven percent of girls in Ethiopia change their menstrual cloths once a day [10].

Most girls in Ethiopia are at risk of getting genitourinary tract infections due to their unhygienic practices during their menstruation period which may lead to further complication if left untreated [11].

Therefore, this study was aimed to assess the knowledge and practice of menstrual hygiene among high school girls in Western Ethiopia. The information obtained from this study will be used by policy makers and stakeholders to identify the awareness and practice of menstrual hygiene so as to provide information about menstruation and menstrual hygiene for high school girls in the study area.

\section{Methods}

\section{Study design, setting and participants}

School based cross- sectional study was employed from May 04 to May 30, 2014 among high school girl students in Nekemte Town, Oromia Region, Western Ethiopia. Nekemte is the capital of East Wollega Zone (Province) located at $331 \mathrm{~km}$ from Addis Ababa. The total population of the town is estimated to be 75,219 of which 38,385 (51 \%) was females. There are ten high schools (4 governmental and 6 non-governmental) in Nekemte town. In this town the total number of students enrolled for $9^{\text {th }}$ and $10^{\text {th }}$ grade levels were 5548 for the academic year 2013-2014 out which 2762 were male and 2756 were female $[12,13]$. Girls studying in $9^{\text {th }}$ and $10^{\text {th }}$ grade were 1400 and 1392 respectively. The girls who attained menarche were included for the study. Girls with visual impairment, evening class students and those who were critically ill and incapable to provide informed consent were excluded from the study.

\section{Sample size and sampling procedures}

The sample size was determined using a formula for estimation of single population proportion with the assumption of $95 \%$ confidence interval, $5 \%$ margin of error, and prevalence of knowledge about menstruation at $51.36 \%$ [14], and design effect of 2. To compensate for the non-response rate, $10 \%$ of the determined sample was added up on the calculated sample size and the final sample size was found to be 845 .

The sampling procedure started by stratifying the schools into two categories, governmental and nongovernmental. The selection of the schools was done randomly. Each school was further stratified by their sections. For selection of representative numbers of students, the ratio of students in the respective types was considered. The sample size was allocated for the schools using population proportion to the sample for each selected school, size being the number of students in each high school ( $9^{\text {th }}$ and $10^{\text {th }}$ grade). Finally, proportional number of participants (students) was selected by simple random sampling technique. The sampling frame was obtained from the student registration books of the respective schools.

\section{Data collection procedures}

To collect data self-administered questionnaires were employed. After reviewing relevant literature questionnaires were adapted and modified [14-19]. The questionnaire was prepared in English language and translated into Afan Oromo, the regional language and then translated back to English by other people who are proficient in both languages to maintain the consistency and content of the questionnaire. Six girls with high- school education were recruited as data collectors. They were given a day training to familiarize them with the objective and relevance of the study, confidentiality of information, participants' rights and informed consent. Three graduate colleagues from health supervised the data collection procedures. Their supervision, involved reviewing all questionnaires at the end of every day, and morning meetings with the data collectors to discuss any problems they encountered during data collection and provide timely remedy.

Students' menstrual knowledge score was calculated out of the 7 knowledge specific questions (Table 2). Each correct response earned one point, whereas any wrong or don't know response attracted no mark and thus the sum score of knowledge was calculated ( 7 points). Accordingly, the mean score of menstrual knowledge $(4.8 \pm 1.67)$ was used to decide the cutoffs of the rank. Good knowledge of menstruation and menstrual hygiene was given to those respondents who scored 5-7 points and Poor Knowledge of menstruation and menstrual hygiene was given to those respondents who scored 0-4 points.

Students' practice of menstrual hygiene score was calculated out of the practice specific questions (Table 2). Each correct response earned one point, whereas any wrong or don't know response attracted no mark. In 
Table 1 Socio-demographic characteristics of high school girls, Nekemte Town, Oromia region, Western Ethiopia, 2014

\begin{tabular}{|c|c|}
\hline Variables (828) & Number (\% \\
\hline \multicolumn{2}{|l|}{ Age category in years } \\
\hline$<=16$ & $539(65.1)$ \\
\hline$>16$ & $289(34.9)$ \\
\hline \multicolumn{2}{|l|}{ Grade } \\
\hline Ninth & $537(64.9)$ \\
\hline Tenth & $291(35.1)$ \\
\hline \multicolumn{2}{|l|}{ Ethnicity } \\
\hline Oromo & 769 (92.9) \\
\hline Amhara & $28(3.4)$ \\
\hline Gurage & $18(2.2)$ \\
\hline Others* & $13(1.6)$ \\
\hline \multicolumn{2}{|l|}{ Religion } \\
\hline Ethiopian Protestant & $420(50.7)$ \\
\hline Ethiopian Orthodox & $292(35.3)$ \\
\hline Ethiopian Catholic & $68(8.2)$ \\
\hline Muslim & $42(5.1)$ \\
\hline Others ${ }^{* *}$ & $6(0.7)$ \\
\hline \multicolumn{2}{|c|}{ Educational status of the Father's $(n=820)$} \\
\hline Can't read and write & $98(12)$ \\
\hline Can read and write & $200(24.4)$ \\
\hline G1-4 & $48(5.9)$ \\
\hline G5-8 & $123(15)$ \\
\hline Secondary & $113(13.8)$ \\
\hline College and above & $238(29)$ \\
\hline \multicolumn{2}{|l|}{ Educational status Mother's $(n=823)$} \\
\hline Can't read and write & $175(21.3)$ \\
\hline Can read and write & $178(21.6)$ \\
\hline G1-4 & $121(14.7)$ \\
\hline G5-8 & $154(18.7)$ \\
\hline Secondary & $97(11.8)$ \\
\hline College and above & $98(11.9)$ \\
\hline \multicolumn{2}{|c|}{ Occupational status of the Mother's $(n=818)$} \\
\hline Housewife & $269(32.7)$ \\
\hline Student & $139(16.9)$ \\
\hline Merchant & $187(22.7)$ \\
\hline Employed in private organization & $28(3.4)$ \\
\hline Governmental employee & $102(12.4)$ \\
\hline Daily laborer & $82(10)$ \\
\hline Others & $16(1.9)$ \\
\hline \multicolumn{2}{|c|}{ Occupational status of the father's $(n=820)$} \\
\hline Farmer & $313(37.8)$ \\
\hline Government employed & 278 (33.6) \\
\hline Merchant & $96(11.6)$ \\
\hline
\end{tabular}

Table 1 Socio-demographic characteristics of high school girls, Nekemte Town, Oromia region, Western Ethiopia, 2014 (Continued)

\begin{tabular}{ll}
\hline Private organization & $48(5.8)$ \\
Daily Laborer & $77(9.3)$ \\
Others**** & $8(1 \%)$ \\
Income (ETB) $(n=808)$ & \\
$<800$ & $215(26.6)$ \\
$800-1000$ & $306(37.9)$ \\
$1001-2000$ & $118(114.6)$ \\
$>2000$ & $169(20.9)$ \\
Mean & 1801 ETB \\
Have radio/TV $(n=828)$ & \\
Yes & $691(83.5)$ \\
No & $137(16.5)$ \\
Earn money from the family $(n=828)$ & $109(13.2)$ \\
Yes & $719(86.8)$ \\
\hline No & \\
* Tigre, Shinasha, Wolyita \\
** Adventist, Wakefeta \\
*** Driver, Waiter, Tailor
\end{tabular}

here, the sum score of practice was calculated (10 points). Where, the mean score of practice of menstrual hygiene $(5.1 \pm 1.57)$ was used to decide the cutoffs of the rank. Good practice of menstrual hygiene was given to those respondents who scored 6-10 points and Poor practice of menstrual hygiene was given to those respondents who scored $0-5$ points.

\section{Data processing and statistical analysis}

Each completed questionnaires was coded on pre-arranged coding sheet by the principal investigator to minimize errors. Data were cleaned and entered into a computer using Epi-info Window version 3.5.1 statistical program. Then the data were exported to SPSS Windows version 20.0 for analysis. The descriptive analysis including proportions, percentages, frequency distribution and measures of central tendency was done.

Initially, bivariate analysis was performed between dependent variable (Knowledge and practice of menstrual hygiene) and each of the independent variables (Sociodemographic variables), one at a time. Their odds ratios $(\mathrm{OR})$ at $95 \%$ confidence intervals $(\mathrm{CI})$ and $P$-values were obtained, to identify important candidate variables for multivariate analysis. All variables found to be significant at bivariate level (at $P$-value $<0.05$ ) were entered in to multivariate analysis using a logistic regression model in order to control for confounding factors.

\section{Ethical considerations}

Ethical clearance and permission was obtained from Wollega University Institutional Research Review Board. 
Permission was secured from each High School through a formal letter. School directors and directresses were briefed on the relevance and objectives of the study. The purpose of the study was explained to the students and written informed consent was obtained from each participant. For those students who were under the age of consent, informed verbal consent was obtained from their parents and assent from the students. Confidentiality of information was maintained by omitting any personal identifier from the questionnaire. Students were informed of their full right to skip or ignore any question or withdraw from their participation at any stage.

\section{Results}

\section{Socio-demographic characteristics of the respondents}

A total of 828 high school girls were participated making a response rate of $98 \%$. Almost two third of $(65.1 \%)$ were in the age group less than or equal to 16 years with median age of 16 years. The majority (92.9\%) of the respondents were from the Oromo ethnic group. Half of the respondents $(50.7 \%)$ were Ethiopian Protestants. Two hundred thirty eight $(29 \%)$ of the respondents' father completed college and above. One hundred seventy eight $(21.6 \%)$ of the respondents' mother can read and write. Nearly one third (32.7\%) of the mothers of the respondents were housewives and three hundred thirteen $(37.8 \%)$ of their fathers were farmers. Their family mean monthly income was Ethiopian birr (ETB) 1801. The majority $(86.8 \%)$ of the respondents didn't get permanent pocket money form their families. Out of the total respondents six hundred ninety one $(83.5 \%)$ of their family owned radio/TV (Table 1).

\section{Knowledge about menstruation and its hygiene}

According to the data obtained from the participants, five hundred four $(60.9 \%)$ of the respondents had good knowledge about menstruation and its hygiene. Out of total six hundred thirty seven $(76.9 \%)$ of girls knew that menstruation was a physiological process, eighty (9.7 \%) of the girls believed that it was a curse from God. Five hundred nineteen $(62.9 \%)$ knew that the cause of menstruation was hormone. More than half, five hundred four $(60.9 \%)$ of the respondents knew the origin of the menstrual blood was from the uterus. Majority six hundred fifty seven $(79.3 \%)$ knew about menstruation before attaining menstruation. Three fourth six hundred twenty two $(75.1 \%)$ of girls knew about menstrual hygiene. Five hundred twenty seven (63.6 \%) knew that there was a foul smell during menstruation (Table 2).

The results of the study revealed that, $67.8 \%$ of the respondents got information about menstruation from their friends, followed by mass media, teachers, from their mothers and books (Fig. 1).
Table 2 Respondents knowledge about menstrual hygiene, Nekemte Town, Oromia region, Western Ethiopia, 2014

\begin{tabular}{ll}
\hline Variables (828) & Number (\%) \\
\hline Menstruation & $637(76.9)$ \\
Physiological process & $52(6.3)$ \\
Pathological process & $80(9.7)$ \\
Curse from god & $59(7.1)$ \\
Don't know & \\
Cause of menstruation & $519(62.7)$ \\
Hormones & $228(27.5)$ \\
Curse of god & $22(2.7)$ \\
Caused by disease & $59(7.1)$ \\
Don't know & \\
Source of menstrual blood & $504(60.9)$ \\
Uterus & $226(27.3)$ \\
Vagina & $17(2.1)$ \\
Bladder & $33(4.0)$ \\
Abdomen & $43(5.2)$ \\
Don't know & $524(39.1)$ \\
Keard about menstruation before attaining menarche & \\
Yes & $657(79.3)$ \\
No & $171(20.7)$ \\
Knew about menstrual hygiene & \\
Yes & \\
No & \\
Nos the & \\
\hline
\end{tabular}

Girls whose mother's education status secondary school and above were 1.51 times more likely had good knowledge about menstruation and menstrual hygiene than their counterparts [AOR $=1.51,95 \% \mathrm{CI}: 1.03-2.22]$. Girls from families with radio and/or TV were more likely to have good knowledge about menstruation and menstrual hygiene when compared to those who had no radio/ TV $[\mathrm{AOR}=2.42,95 \%$ CI: $1.64-3.56]$ (Table 3).

\section{Hygienic practices during menstruation}

As to the data obtained, out of the total respondents, 330 (39.9\%) of the respondents had good practice on menstrual hygiene. Majority $678(82.2 \%)$ of girls were 




Fig. 1 Respondents' sources of information about menstruation in Nekemte Town, Oromia region, Western Ethiopia, 2014

using absorbent material during menstruation and two third $548(66.2 \%)$ of girls were using commercial made sanitary pads as absorbent material during menstruation. Out of one hundred fifty seven girls who were using clothes eighty three $(52.9 \%)$ of the respondents were washing clothes with soap and water. Seventy one $(45.2 \%)$ of the respondents dried their washed clothes in sunlight. Half 430 (51.9 \%) of girls change their pads or clothes three and above times per day. One hundred sixty seven $(20.2 \%)$ of the respondents were disposing their used sanitary pads in dustbin. One third 274 (33.3\%) of girls use paper to dispose the pads by wrapping. Two third 557 (67.3\%) of respondents were taking bath daily with soap during menstruation. Six hundred fifty seven $(83.5 \%)$ of the girls clean their external genitalia during menstruation with soap and water (Table 4).

Girls whose mother's educational status was secondary school and above were 2 times more likely to have good practice of menstrual hygiene than their counterparts [AOR $=2.03,95 \%$ CI: 1.38-2.97]. Respondents whose mother's occupations come under category of others were less likely to have good practice of menstrual hygiene than housewives [AOR $=0.66,95 \% \mathrm{CI}: 0.47-0.91]$. Girls who earn permanent pocket money from their families were nearly three times more likely to have good practice about menstrual hygiene compared to those who don't earn permanent pocket money from their families $[\mathrm{AOR}=2.73,95 \% \mathrm{CI}: 1.76-4.26$ ] (Table 5).

\section{Discussion}

In this study, more than half $(60.9 \%)$ of the students had good knowledge about menstruation and menstrual hygiene. The majority $(76.9 \%)$ girl knew that menstruation was a physiological process, whereas $9.7 \%$ them believed that it was a curse from God. The findings were higher than those in previous studies done in Ethiopia,

Table 3 Predictors of knowledge about menstruation and menstrual hygiene among high school girls' of Nekemte town, Oromia region, Western Ethiopia, 2014

\begin{tabular}{|c|c|c|c|c|}
\hline \multirow[t]{2}{*}{ Characteristics } & \multicolumn{2}{|l|}{ Knowledge } & \multirow{2}{*}{$\begin{array}{l}\text { Crude OR } \\
\mathrm{OR}(\mathrm{Cl})\end{array}$} & \multirow{2}{*}{$\begin{array}{l}\text { Adjusted OR } \\
\text { OR }(\mathrm{Cl})\end{array}$} \\
\hline & Good (\%) & Poor (\%) & & \\
\hline \multicolumn{5}{|c|}{ Educational status of the mothers } \\
\hline Below and Primary & $361(57.5 \%)$ & $267(42.5 \%)$ & 1 & 1 \\
\hline Secondary and above & $138(70.8 \%)$ & $57(29.2 \%)$ & $1.79(1.27-2.53)$ & $1.51(1.02-2.22)^{*}$ \\
\hline \multicolumn{5}{|c|}{ Educational status of the father } \\
\hline Below and Primary & $271(57.8 \%)$ & $198(42.2 \%)$ & 1 & 1 \\
\hline Secondary and above & $233(66.4 \%)$ & $118(33.6 \%)$ & $1.44(1.08-1.92)$ & $1.07(0.76-1.50)$ \\
\hline \multicolumn{5}{|c|}{ Occupation status of father's } \\
\hline Government Employed & $189(68.0 \%)$ & $89(32.0 \%)$ & $1.55(1.14-2.10)$ & $1.19(0.84-1.68)$ \\
\hline Others & $315(57.8 \%)$ & $230(42.2 \%)$ & 1 & 1 \\
\hline \multicolumn{5}{|l|}{ Have Radio/TV } \\
\hline Yes & $449(65.0 \%)$ & $242(35.0 \%)$ & $2.77(1.90-4.03)$ & $2.42(1.64-3.56)^{*}$ \\
\hline No & 55 (40.1\%) & 82 (59.9\%) & 1 & 1 \\
\hline
\end{tabular}

Key $={ }^{*}$ statistically significant $(P$-value $<0.05) ; 1=$ Reference category 
Table 4 Respondents menstrual hygienic practices during menstruation in Nekemte Town, Oromia Region, Western Ethiopia, 2014

\begin{tabular}{ll}
\hline Parameters of practice & Number (\%) \\
\hline Uses absorbent materials during menstruation & $678(82.2)$ \\
Uses commercially made sanitary pad as absorbent & $548(66.2)$ \\
material during menstruation & \\
Clean clothes with soap and water & $83(52.9)$ \\
Dry cloths in sunlight & $71(45.2)$ \\
Changing pads or cloths more than three times & $430(51.9)$ \\
and above during menstruation & \\
Disposes used sanitary pads in dustbin & $167(20.2)$ \\
Uses paper to dispose the pads by wrapping & $274(33.3)$ \\
Takes bath daily with soap during menstruation & $557(67.3)$ \\
Clean external genitalia during menstruation & $787(95)$ \\
Cleans external genitalia with water and soap & $657(83.5)$ \\
during menstruation & \\
Practice (summary index) & \\
Good practice & $330(39.9)$ \\
Poor practice & $498(60.1)$ \\
\hline
\end{tabular}

Nigeria, and Nepal, which were $51.36 \%, 4.0 \%$, and $40.6 \%$, respectively [14-16]. This difference could be due to minimal communication in families about menstruation and menstrual hygiene issues. Contrary to the findings of this study, high knowledge about menstrual hygiene was obtained in a study done in Amhara, northern Ethiopia, which was $90.7 \%$ [17], possibly due to information provided about menstruation and menstrual hygiene by schools and families.

Almost $68 \%$ of the respondents got information about menstruation from their friends $(67.8 \%)$, followed by mass media (57\%); teachers, mothers, and books were the main sources of menstrual information in this study. These findings are consistent with the results from studies done in Egypt and India [18, 19]. A possible explanation for this similarity may be that girls discuss menstruation and its hygiene with their friends and peers openly.

In this study, multivariable analysis showed that girls whose mothers' educational status was secondary school and above were 1.51 times more likely to had good knowledge about menstruation and menstrual hygiene than their counterparts. A similar study done in western Nigeria showed that parental education was positively associated with girls' menstrual knowledge [20]. This study disagrees with results obtained from a study in Sokot, Nigeria [21]. The reason could be that educated mothers may provide information about menstruation and menstrual hygiene to their daughters. Girls from educated families may discuss openly about sexual and reproductive health issues including menstruation.

The mass media play a prominent role in the dissemination of reproductive health information including

Table 5 Predictors of practice about menstruation and menstrual hygiene among high school girls' of Nekemte town, Oromia region, Western Ethiopia, 2014

\begin{tabular}{|c|c|c|c|c|}
\hline \multirow[t]{2}{*}{ Characteristics } & \multicolumn{2}{|l|}{ Practice } & \multirow{2}{*}{$\begin{array}{l}\text { Crude OR } \\
\text { OR (Cl) }\end{array}$} & \multirow{2}{*}{$\begin{array}{l}\text { Adjusted OR } \\
\text { OR }(\mathrm{Cl})\end{array}$} \\
\hline & Good (\%) & Poor (\%) & & \\
\hline \multicolumn{5}{|c|}{ Educational status of the mothers } \\
\hline Below and Primary & $224(35.7 \%)$ & $404(64.3 \%)$ & 1 & 1 \\
\hline Secondary and above & $102(52.3 \%)$ & $93(47.7 \%)$ & $1.98(1.43-2.74)$ & $2.03(1.38-2.97)^{*}$ \\
\hline \multicolumn{5}{|c|}{ Educational status of the father } \\
\hline Below and Primary & $166(35.4 \%)$ & $303(64.6 \%)$ & 1 & 1 \\
\hline Secondary and above & $164(46.7 \%)$ & $187(53.3 \%)$ & $1.60(1.21-2.12)$ & $1.26(0.90-1.78)$ \\
\hline \multicolumn{5}{|c|}{ Occupational status of the mother } \\
\hline House wife & $127(47.2 \%)$ & $142(52.8 \%)$ & 1 & \\
\hline Others & 201 (36.7 \%) & $347(63.3 \%)$ & $0.65(0.48-0.87)$ & $0.66(0.47-0.91)^{*}$ \\
\hline \multicolumn{5}{|l|}{ Monthly income } \\
\hline$<800$ & 67 (31.2 \%) & $148(68.8 \%)$ & 1 & 1 \\
\hline $800-1000$ & $129(42.2 \%)$ & $177(57.8 \%)$ & $1.61(1.12-2.32)$ & $1.46(0.99-2.15)$ \\
\hline $1001-2000$ & $52(44.1 \%)$ & $66(55.9 \%)$ & $1.74(1.09-2.77)$ & $1.20(0.73-1.99)$ \\
\hline$>2000$ & $68(40.2 \%)$ & $101(59.8 \%)$ & $0.65(1.49-2.27)$ & $1.24(0.80-1.93)$ \\
\hline \multicolumn{5}{|c|}{ Earn permanent pocket money from parents or relatives } \\
\hline Yes & $66(60.6 \%)$ & $43(39.4 \%)$ & $2.65(1.76-4.00)$ & $2.73(1.76-4.26)^{*}$ \\
\hline No & $264(36.7 \%)$ & $455(63.3 \%)$ & 1 & 1 \\
\hline
\end{tabular}

Key $={ }^{*}$ statistically significant ( $p$-value $\left.<0.05\right), 1=$ Reference category 
menstruation and menstrual hygiene $[7,18,22]$. The knowledge level of menstrual hygiene appears to be increasing with an increase in time spent on watching TV/ listening to radio [23]. Thus the finding of this study showed that the availability of mass media (Radio/ TV) at home as the highest predictor of good knowledge of menstrual hygiene. In fact, the reason might be mass media may be endorsed to the effect of technology on increasing knowledge and gaining needed information about menstrual hygiene.

In this study, three hundred thirty (39.9\%) of the respondents had good practice of menstrual hygiene. The finding of this study was lower than studies conducted in Ethiopia and North western Nigeria which were $90.9 \%$ and $88.7 \%$, respectively $[15,17]$. Comparatively, lower level of practice of menstrual hygiene was recorded from similar study conducted on Gujjar girls it was indicated that only $3.1 \%$ of the study participants practice good menstrual hygiene [24]. Thus, the reason for the observed difference could be due to low awareness and communication of menstrual hygiene by Gujjar girls which affects their menstrual hygienic practice.

Educational status of the parents was important predictors of menstrual hygienic practice [20]. In the present study girls whose mothers' educational statuses was secondary and above were two times more likely to have good practice of menstrual hygiene than their counterparts. This aligns with the studies done in Ethiopia, Lebanon, India and Nigeria $[14,21,25,26]$. The possible explanation might be that educated mothers may have awareness on practice of menstrual hygiene and they may have provided materials for their daughters to clean their genitalia during menstruation.

This study indicated that respondents whose mothers' occupation others were less likely to have good practice of menstrual hygiene compared to those of housewives. In contrast, a study done in Nigeria indicated that employment of mothers showed significant statistical association with respect to the practice of good menstrual hygiene [21]. The difference might be due to that majority of occupation of the respondent mothers in Nigeria were business women and civil servants. Those mothers who have work outside home may have exposure and access to information that can increase knowledge and awareness of reproductive issues including menstruation and menstrual hygienic practice.

In this study girls who earn permanent pocket money from their families were nearly three times more likely to have good practice about menstrual hygiene compared to those who don't earn permanent pocket money from their families. Studies done in Ethiopia and South
India were consistent with our study [14, 27]. This could be due to girls who get money from their parents can easily buy sanitary napkins for their menstrual hygiene.

The limitation of this study was the cross-sectional nature of the data that could obscure the causal effect relationships of different factors and it lacks qualitative data. Basically, the study addressed the sensitive issue about menstrual hygiene and the possibility of social desirability bias is unavoidable even if we have tried our best to minimize it.

\section{Conclusions and recommendations}

Half of the participants had good knowledge of menstruation and menstrual hygiene. The practice of menstrual hygiene was low (39.9 \%). Indeed, the findings showed a significant positive association between good knowledge of menstruation and educational status of the mother, having radio/TV. The educational status of the mother and the earning of permanent pocket money from families or relatives revealed significant positive association with good practice of menstrual hygiene. Awareness regarding the need for information about good menstrual practices is very important. Mass media should also emphasize on health information about menstrual hygiene. Therefore, policy makers and stakeholders should setup health education program to create awareness and practice of good menstrual hygiene (Additional file 1).

\section{Additional file}

Additional file 1: Structured Questionnaire (English Version). (DOCX $49 \mathrm{~kb})$

\section{Competing interests}

The authors declare that they have no competing interests.

\section{Authors' contributions}

SPU, TT, JM carried out the research from conception to the write up of the final draft of the article. All authors read and approved the final manuscript.

\section{Authors' information}

SPU: is Lecturer of child health Nursing, Department of Nursing and Midwifery, College of Medical and Health Sciences, Wollega University, Ethiopia.

$\Pi \mathrm{T}$ is Lecturer of Reproductive and Maternal Health, Department of Nursing and Midwifery, College of Medical and Health Sciences, Wollega University, Ethiopia.

JM is Lecturer of child health Nursing, Department of Nursing and Midwifery, College of Medical and Health Sciences, Wollega University, Ethiopia.

\section{Acknowledgements}

We would like to acknowledge Wollega University for funding this research project (Ref. No: WU-RD-117/2006 E.C; Dated: 03/07/2006 E.C). Our sincere gratitude also goes to all supervisors, data collectors and study participants for their cooperation and support during the study period.

Received: 22 February 2015 Accepted: 6 October 2015

Published online: 14 October 2015 


\section{References}

1. Dasgupta A, Sarkar M. Menstrual hygiene: How hygienic is the adolescent girl? Indian J Community Med. 2008;33(2):77-80.

2. Water Aid: Menstrual hygiene and management an issue for adolescent school girls. March 2009. Available from: www.wateraid.org/nepal.

3. Narayan KA, Srinivasa DK, Pelto PJ, Veerammal S. Puberty rituals, reproductive knowledge and health of adolescent schoolgirls in South India. Asia-Pac Popul J. 2001;16(2):225-38.

4. Ten VA. Menstrual Hygiene: A Neglected Condition for the Achievement of Several Millennium Development Goals, European Commission -Europe Aid. 2007.

5. Reid G, Bruce AW. Urogenital infections in women: can probiotics help? Postgrad Med J. 2003;79:428-32.

6. Baisley K, Changalucha J, Weiss HA, Mugeye K, Everett D, Hambleton I, et al. Bacterial vaginosis in female facility workers in north-western Tanzania: prevalence and risk factors. Sex Transm Infect. 2009;85:370-5.

7. Adinma ED, Adinma J. Perceptions and practices on menstruation amongst Nigerian secondary school girls. Afr J Reprod Health. 2008;12(1):74-83.

8. Aniebue UU, Aniebue PN, Nwankwo TO. The impact of pre-menarcheal training on menstrual practices and hygiene of Nigerian school girls. Pan Afr Med J. 2009;2(9).

9. Desalegn T, Berihun M, Abay M: Age at menarche and the menstrual pattern of secondary school adolescents in northwest Ethiopia. BMC Women's Health 2009, 9(29). doi:10.1186/1472-6874-9-29.

10. Sarah $H$, Thérèse $M$. Sue: a resource for improving menstrual hygiene around the world. WaterAid. 2012;22-43. Available at: https:// www.google.com/?gws_rd=ssl\#newwindow=1amp; $q=A+$ resource + for +improving+menstrual+hygiene+around+the+world.+2012.+22-43.

11. Annabel S, Abebaw F, Worku A, Woldemariam G, Helen A, Behailu G, et al. Ethiopia Young Adult Survey: A Study in Seven Regions. Addis Ababa, Ethiopia: Population Council; 2010.

12. FDRE C. The 2007 population and Housing Census of Ethiopia. Addis Ababa: Results for Oromia Region Part V. Statistical Report on Population and Household size of Kebeles; 2008.

13. Education bureau of Nekemte Town. Students Enrolment Data. Education Bureau. Ethiopia: Oromia region; 2013-2014.

14. Tegegne T, Sisay M. Menstrual hygiene management and school absenteeism among female adolescent students in Northeast Ethiopia. BMC Public Health 2014,14(1118). doi:10.1186/1471-2458-14-1118.

15. Lawan U, Nafisa W, Musa A. Menstruation and menstrual hygiene amongst adolescent school girls in Kano Northwestern Nigeria. Afr J Reprod Health. 2010;14(3):201-7.

16. Adhikari $P$. Knowledge and practice regarding menstrual hygiene in rural adolescent girls of Nepal. Kathmandu Univ Med J. 2007;5(19):382-6.

17. Teklemariam G. Practice of menstrual hygiene and associated factors among female Mehalmeda high school students in Amhara Regional State, Ethiopia. Sci J Public Health. 2014;2(3):189-95.

18. El-Gilanya A, Badawib K, EL-Fedawyb S. Menstrual hygiene among adolescent school girls in Mansoura, Egypt. Reprod Health Matter. 2005;13:147-52.

19. Bhattacherjee S, Ray K, Biswas R, Chakraborty M. Menstruation. Experiences of adolescent slum dwelling girls of siliguri city, west Bengal. India. J Basic Clinic Reprod Sci. 2013;2(2):85-91.

20. Abioye EA. Menstrual knowledge and practices amongst secondary school girls in lle Ife, Nigeria. J R Soc Health. 2000;20:23-6.

21. Oche O, Umar S, Gana J, Ango T. Menstrual health: the unmet needs of adolescent girls' in Sokoto, Nigeria. Sci Res Essays. 2012;7(3):410-8.

22. Adinma JIB, Agbai AO, Okeke AO. Influence of study discipline on the sexual behaviour of Nigerian female students. West Afr J Med. 1998;17(2):70-4.

23. Rani P. Knowledge and practices of menstrual hygiene among married adolescents and young women in chittoor district of Andra Pradesh: India. J Nurs Health Sci. 2014;3(2):06-15.

24. Dhingra R, Kumar A. Knowledge and practices related to menstruation among tribal (Gujjar) adolescent girls. Etho-Med. 2009;3(1):43-8.

25. Santina T, Wehbe N, Ziade FM, Nehme M. Assessment of beliefs and practices relating to menstrual hygiene of adolescent girls in Lebanon Int J Health Sci Res. 2013;3(12):75-88.

26. Patavegar BN, Kapilashrami MC, Rasheed N, Pathak R. Menstrual hygiene among adolescent school girls: an in-depth cross-sectional study in an urban community. Int J Health Sci Res. 2014;4(11):15-21.

27. Omidvar S, Begum K. Factors influencing hygienic practices during menses among girls from south India - a cross sectional study. Int J Coll Res Inter Med Pub Hlth. 2010;2(12):411-23.

\section{Submit your next manuscript to BioMed Central and take full advantage of:}

- Convenient online submission

- Thorough peer review

- No space constraints or color figure charges

- Immediate publication on acceptance

- Inclusion in PubMed, CAS, Scopus and Google Scholar

- Research which is freely available for redistribution

Submit your manuscript at www.biomedcentral.com/submit 